\title{
Direct Analysis in Real Time (DART) Mass Spectrometry of Nucleotides and Nucleosides: Elucidation of a Novel Fragment $\left[\mathrm{C}_{5} \mathrm{H}_{5} \mathrm{O}\right]^{+}$and Its In-Source Adducts
}

\author{
Matthew Curtis, Mikael A. Minier, Priyanka Chitranshi, \\ O. David Sparkman, Patrick R. Jones, and Liang Xue \\ Department of Chemistry, University of the Pacific, Stockton, California, USA
}

Direct analysis in real time (DART) mass spectrometry is a recently developed innovative technology, which has shown broad applications for fast and convenient analysis of complex samples. Due to the ease of sample preparation, we have recently initiated an investigation of the feasibility of detecting nucleotides and nucleosides using the DART-AccuTOF instrument, which we will refer to as the DART mass spectrometer. Our experimental results reveal that the ions representing the intact molecules of nucleotides are not detectable in either positive-ion or negative-ion mode. Instead, all four natural nucleotides fragment in the DART ion source, and a common fragment ion, $\left[\mathrm{C}_{5} \mathrm{H}_{5} \mathrm{O}\right]^{+}(1)$, is observed, which is probably formed via multiple-elimination reactions. Interestingly, $\mathbf{1}$ can form adducts with nucleobases in different molar ratios in the DART ion source. In contrast to nucleotides, the ions representing the intact molecules of nucleosides are detected in both positive-ion and negative-ion mode using DART mass spectrometry. Surprisingly, the fragmentation pattern of nucleosides is different from that of nucleotides in the DART ion source. In the cases of nucleosides (under positive-ion conditions), the production of $\mathbf{1}$ is not observed, indicating that the phosphate group plays an important role for the multiple eliminations observed in the spectra of nucleotides. The in-source reactions described in the present work show the complexity of the conditions in the DART ion source, and we hope that our results illustrate a better understanding about DART mass spectrometry. (J Am Soc Mass Spectrom 2010, 21, 1371-1381) (C) 2010 American Society for Mass Spectrometry

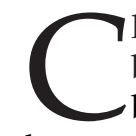

haracterization of natural and modified nucleobases, nucleotides, and nucleosides (Figure 1) has been in focus of research in the past decade, mainly because they can be used as biomarkers for diagnostic purposes [1-4]. For instance, 8-oxo-deoxyguanosine (OG) has been used to determine the level of oxidative stress in biological organisms, which is associated with the mechanism of carcinogenesis [1,5]. Over the years, several methods including high-performance liquid chromatography (HPLC), capillary electrophoresis, gas chromatography (GC), mass spectrometry (MS), and autoradiography have been developed for detection and quantitation of nucleotides and nucleosides [6-9]. Of these techniques, the methods using mass spectrometry have gained the most of the attention partially because of the accurate mass values that mass spectrometry can provide [10]. Nucleotides and nucleosides can be unambiguously determined based on the accurate masses of ions representing the intact molecules and quantitated through

Address reprint requests to Dr. L. Xue, Department of Chemistry, University of the Pacific, 3601 Pacific Avenue, Stockton, CA 95211, USA. E-mail: lxue@pacific.edu the use of isotope-labeled internal standards. Cadet and coworkers developed a detection method of nucleosides utilizing HPLC in conjunction with mass spectrometric detection (LC/MS) after enzymatically digesting the target DNA into nucleosides [7]. Dizdaroglu et al. reported the analysis of nucleobases using GC after chemically releasing the modified bases from DNA followed by derivatization [8]. Even though there is some disagreement regarding how these measurements are made [6-8], both methods have become classic examples; however, most of the methods for detecting nucleotides, nucleosides, and nucleobases using mass spectrometry are time-consuming and require precautions during sample preparation [10].

To overcome the time-consuming measurements in the above referenced methods while employing the accurate mass measure of mass spectrometry, novel techniques must be used. In our search for such techniques, direct analysis in real time (DART) mass spectrometry, which was recently developed by JEOL and IonSense for instantaneously analyzing gases, liquids, and solids at ground potential in open air, came to our attention. The major breakthrough/advantage of this 


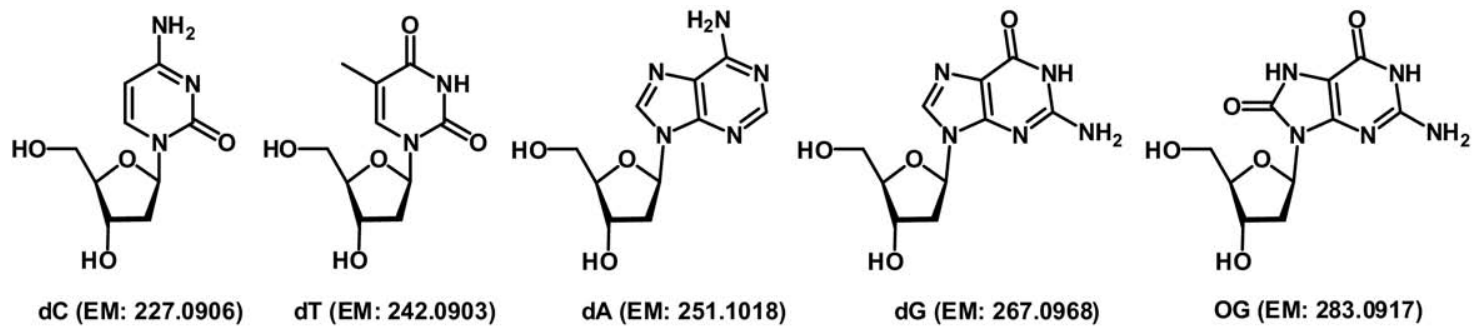<smiles>Nc1ccn(C2CC(O)C2COP(=O)([O-])O)c(=O)n1</smiles>

dCMP (EM: 306.0497)<smiles>Nc1cc[nH]c(=O)n1</smiles>

C (EM: 111.0433)

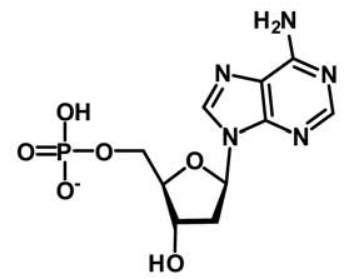

dAMP (EM: 330.0609)<smiles>Cc1c[nH]c(=O)[nH]c1=O</smiles>

$T$ (EM: 126.0429)

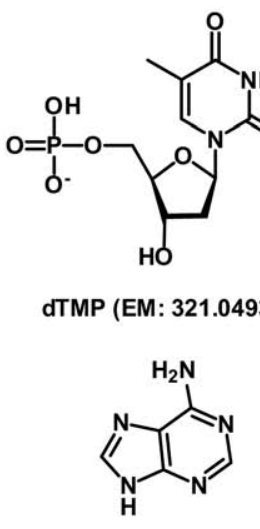

$A(E M: 135.0545)$

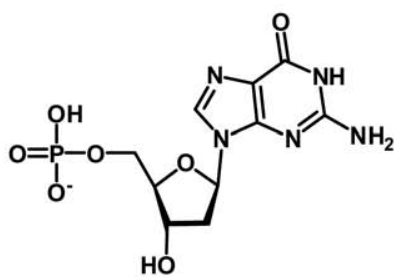

dGMP (EM: 346.0558)

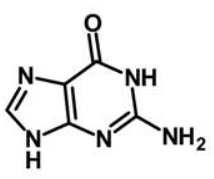

G (EM: 151.0494)

Figure 1. Representative nucleosides, nucleotides, and nucleobases with exact mass (EM).

technique is that it adopts a new ion source that does not operate in vacuum as many classic mass spectrometer ion sources do [11]. Recent reports show that ionization mechanisms in the DART source are complicated [12-14]. The ionized analyte molecules generated in either positive-ion or negative-ion mode can be detected by an atmospheric pressure ionization mass spectrometer (i.e., Accu-TOF-LC). Due to this unique ionization under open-air conditions, analytes used in the DART mass spectrometer require much simpler and less restricted sample preparation. Numerous methods have been developed to rapidly analyze various samples using DART mass spectrometry in the past few years [11, 15-20]. For instance, Sparkman and coworkers reported the use of it for rapid analysis of melamine in contaminated pet food [16]. Haefliger and Jeckelmann used DART mass spectrometry to analyze flavors and fragrances on fabric and hair and in chewing gum [18]. Olson and coworkers even analyzed the selfassembled monolayers on gold surfaces using DART mass spectrometry [21].

Although many types of analytes have been studied, information on analyzing nucleotides and nucleosides using DART mass spectrometry is limited. In this paper, we present evidence of a unique fragmentation pattern of nucleotides and in-source adducts formed between the corresponding fragments, which were discovered during our investigation of the feasibility of detecting DNA nucleotides and nucleosides using DART mass spectrometry. Plausible mechanisms for the fragmentation and the in-source addition reactions are proposed. To the best of our knowledge, this is the first report of such fragmentation produced from nucleotides in DART mass spectrometry. The in-source addition reactions described in this paper should also provide new insights into the possible chemistry present in the DART ion source.

\section{Experimental}

For simplicity, 5'-monophosphate 2'-deoxynucleotides and $2^{\prime}$-deoxynucleosides in this paper are referred as nucleotides and nucleosides, respectively. Unless otherwise specified, nucleotides and nucleoside, including isotope-labeled ones were purchased from Aldrich (St. Louis, MO, USA) or Fisher Scientific (Pittsburgh, PA, USA) and used without further purification. Solvents (water and methanol) were of HPLC grade.

A JEOL Accu-TOF LC time-of-flight mass spectrometer (JEOL, Peabody, MA, USA) equipped with a DART ion source (IonSense, Saugus, MA, USA) was used for this study. The Accu-TOF was tuned to have a resolving power of $\sim 7000$ (FWHM) using reserpine directly infused into the JEOL electrospray ion source. To acquire collisionally activated dissociation (CAD), the potential of the orifice 1 was adjusted to $80 \mathrm{~V}$, making a $65 \mathrm{~V}$ potential difference between orifice 1 and orifice 2, the energy which is enough to fragment non-covalently bound adducts. An increased peak voltage value of 600 $\mathrm{V}$ was used to avoid collecting lower $\mathrm{m} / \mathrm{z}$ background ions and thereby provide a better detection limit of the Accu-TOF. The DART source was operated with helium gas to produce the excited-state species, and the helium flow was set to 12 , using the IonSense software, with a 
flow factor of 2.2. The orientation of the DART cartridge to orifice 1 was optimized to produce either a strong protonated water dimer signal for positive-ion acquisitions, or a strong $\mathrm{O}_{2}{ }^{-}$signal, for negative-ion acquisitions. For positive-ion analyses, the needle, the discharge electrode, and the grid electrode were set to 3000 , 250, and $150 \mathrm{~V}$, respectively. For negative-ion analyses, the needle, the discharge electrode, and the grid electrode were set to $-3500,-250$, and $-450 \mathrm{~V}$, respectively. The temperature of the helium stream was set to $200{ }^{\circ} \mathrm{C}$ or $250{ }^{\circ} \mathrm{C}$ depending on the analyte of interest as described in the result section.

The samples (described below) were introduced into the DART sample gap using the closed-end of a meltingpoint capillary tube that was directly dipped into the sample vial. For each sample, the capillary tube was held close to the DART cap for about $6 \mathrm{~s}$. Within each data acquisition, multiple spectra were collected from a solution of polyethylene glycols in various sizes (PEG 200, PEG 600, and PEG 1000) in methanol for mass calibration. For the conjugate addition reactions between a sample and a model amine, several drops of the amine of interest were placed in a glass tube with a hole directed upwards from underneath the sample gap. Nitrogen gas was then blown into the tube to aspirate the amine vapor into the sample gap while simultaneously introducing the sample using a capillary tube from above the glass tube in the excited helium stream. A graphic presentation of this device is shown in Figure S-1 of the Supporting Information, which can be found in the electronic version of this article.

For pyrolysis of dAMP or dCMP, the nucleotide $(\sim 5 \mathrm{mg})$ was placed in a $1 \mathrm{~mL}$ amber glass ampoule, and the ampoule was placed under vacuum with $\mathrm{P}_{2} \mathrm{O}_{5}$ at $69{ }^{\circ} \mathrm{C}$ overnight to remove as much trace water as possible. The ampoule containing dAMP or dCMP was then sealed under vacuum with a torch. After being heated in an oven at $220^{\circ} \mathrm{C}$ for $5 \mathrm{~min}$, the nucleotide was removed from the ampoule and dissolved with a mixture of methanol and water in a 50/50 ratio. The resulting nucleotide solutions were introduced into the electrospray ion source of the AccuTOF mass spectrometer. The injection volume was $20 \mu \mathrm{L}$, and the flow rate was $50 \mu \mathrm{L} \mathrm{min}^{-1}$. The needle voltage was $3500 \mathrm{~V}$, and the temperatures for the desolvation chamber and orifice 1 were $15^{\circ} \mathrm{C}$ and $80^{\circ} \mathrm{C}$, respectively. The nitrogen gas flow for the drying gas and the nebulizing gas were $1.3 \mathrm{~L} \mathrm{~min}^{-1}$ and $2.0 \mathrm{~L} \mathrm{~min}^{-1}$, respectively.

The procedures for measuring nucleotides mixed with isotope-labeled nucleotides or cysteine are as follows. The nucleotide of interest was mixed with an isotope-labeled nucleotide or cysteine in a 1:1 molar ratio by dissolving the solid mixture in a 50/50 methanol/water solution. Melting point capillaries were dipped into the individual solutions and then allowed to air dry at room-temperature before placing them in the DART sample gap. The instrument settings were the same as described in the normal analyses.

\section{Results and Discussion}

\section{Characterization of Nucleosides in Positive-Ion or Negative-Ion Mode}

All four nucleosides were introduced to the DART ion source in positive-ion or negative-ion mode in a heated helium stream $\left(200^{\circ} \mathrm{C}\right.$ or $\left.250^{\circ} \mathrm{C}\right)$. The resulting DART mass spectra of nucleosides were mostly as expected. The ions representing the protonated intact molecules of nucleosides in positive-ion mode (Figure S-2 of the Supporting Information), and the ions representing the oxygen adducts of nucleosides in negative-ion mode (Figure S-3 of the Supporting Information) were readily detected for all of the nucleosides using the DART mass spectrometer with the only exception being $d G$ in negative-ion mode, which produced a not-so-easily explainable spectrum compared with those of the other three nucleosides, suggesting that the chemistry associated with $\mathrm{dG}$ in negative-ion mode is complicated. We also noted that the mass spectrum of dG in positive-ion mode consists of more fragment-ion peaks than those of the other nucleosides. A closer examination of the mass spectra of $\mathrm{dA}, \mathrm{dC}, \mathrm{dT}$, and $\mathrm{dG}$ obtained in both positiveion and negative-ion mode revealed the presence of the intense peaks representing nucleobases, indicating the involvement of depurination or depyrimidination in these DART experiments. In addition, the protonated dimers of nucleosides were clearly represented in the spectra of $\mathrm{dC}$ and $\mathrm{dT}$ in positive-ion mode.

\section{Fragmentation of Nucleotides in Positive-Ion Mode}

In positive-ion mode, the mass spectra acquired using DART mass spectrometry of nucleotides are dramatically different from those of nucleosides. No ions representing the intact molecules of nucleotides were observed when the helium stream was heated to either 200 or $250^{\circ} \mathrm{C}$, a temperature which was chosen for obtaining significant ion abundances from the nucleosides. Instead, the mass spectra of the nucleotides exhibited peaks representing ions associated with their fragmentation. Attempts to acidify the nucleotide sodium phosphate salts to increase their volatility did not result in peaks representing the intact molecules of nucleotides (spectra not shown). Peaks representing the protonated nucleobases were shown in the mass spectra of all four nucleotides, indicating that the fragmentation involves a depurination or depyrimidination process. More importantly, consecutive peaks with an increment of 80 $\mathrm{m} / \mathrm{z}$ units were observed in the spectra of dCMP and dAMP in positive-ion mode. In the case of the mass spectra resulting from the analysis of dTMP and dGMP, such a peak pattern was not observed, and only peaks representing the protonated nucleobases, the nucleobase dimers, as well as the protonated nucleosides were detected in positive-ion mode. Spectra with accurate masses and the relationships of the ions with their corresponding elemental compositions are listed in Fig- 
ure 2. Explanation of the peak pattern starts from an understanding of the production of the fragment ion with $m / z 81.034$ in the experiments of dAMP, dCMP,
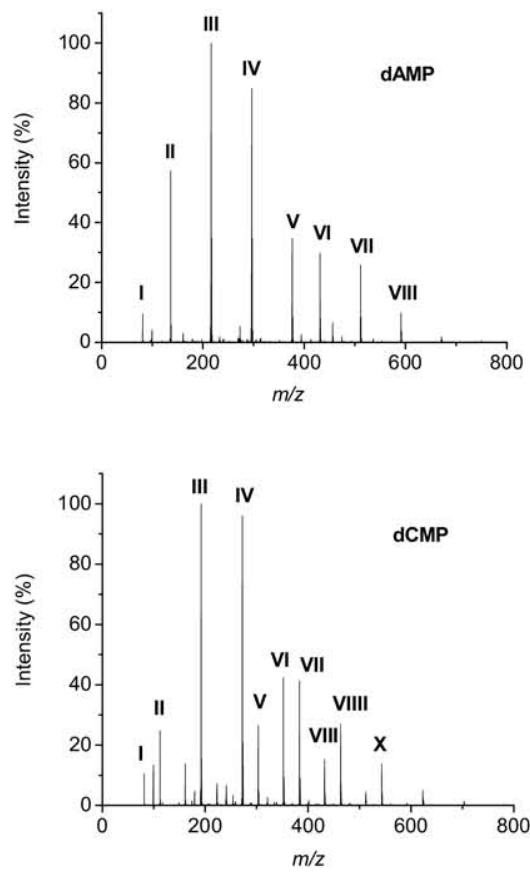

and dTMP. A proposed scheme for the interpretation of this ion using dCMP as example is outlined in Scheme 1. In this scheme, dCMP undergoes elimination reac-
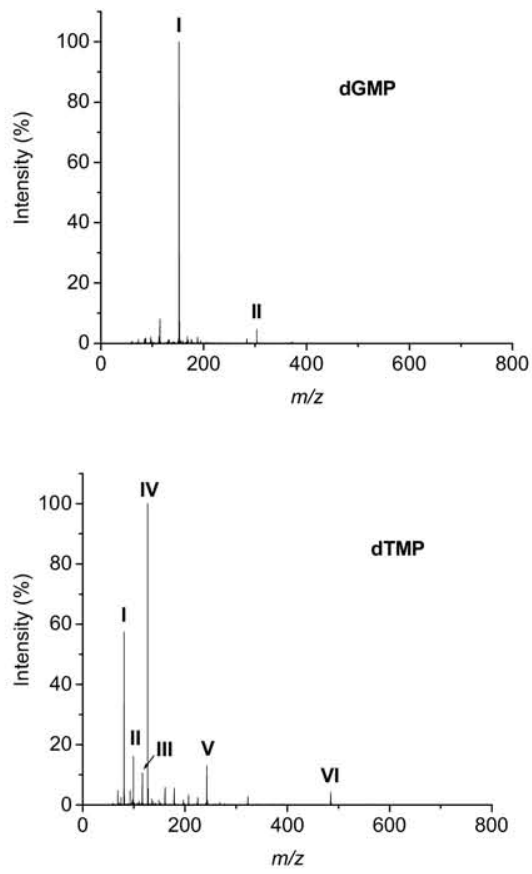

\begin{tabular}{|c|c|c|c|c|c|}
\hline Ion No. & Ion Assignment & Formula & Calculated & Observed & Error (ppm) \\
\hline \multicolumn{6}{|c|}{ dAMP } \\
\hline$\overline{\mathrm{I}}$ & 1 & $\mathrm{C}_{5} \mathrm{H}_{5} \mathrm{O}^{+1}$ & 81.0335 & 81.0344 & +11.1 \\
\hline II & {$[\mathrm{A}+\mathrm{H}]^{+}$} & $\mathrm{C}_{5} \mathrm{H}_{6} \mathrm{~N}_{5}^{+1}$ & 136.0618 & 136.0611 & -5.14 \\
\hline III & {$[\mathrm{A}+1]^{+}$} & $\mathrm{C}_{10} \mathrm{H}_{10} \mathrm{~N}_{5} \mathrm{O}^{+1}$ & 216.0880 & 216.0873 & -3.24 \\
\hline IV & {$[\mathrm{A}+\mathbf{1}+\mathbf{1}-\mathrm{H}]^{+}$} & $\mathrm{C}_{15} \mathrm{H}_{14} \mathrm{~N}_{5} \mathrm{O}_{2}^{+1}$ & 296.1142 & 296.1151 & +3.04 \\
\hline V & {$[\mathrm{A}+\mathbf{1}+\mathbf{1}+\mathbf{1}-2 \mathrm{H}]^{+}$} & $\mathrm{C}_{20} \mathrm{H}_{18} \mathrm{~N}_{5} \mathrm{O}_{3}{ }^{+1}$ & 376.1404 & 376.1440 & +9.57 \\
\hline VI & {$[2 \mathrm{~A}+\mathbf{1}+\mathbf{1}-\mathrm{H}]^{+}$} & $\mathrm{C}_{20} \mathrm{H}_{19} \mathrm{~N}_{10} \mathrm{O}_{2}^{+1}$ & 431.1687 & 431.1681 & -1.39 \\
\hline VII & {$[2 \mathrm{~A}+\mathbf{1}+\mathbf{1}+\mathbf{1}-2 \mathrm{H}]^{+}$} & $\mathrm{C}_{25} \mathrm{H}_{23} \mathrm{~N}_{10} \mathrm{O}_{3}{ }^{+1}$ & 511.1949 & 511.1940 & -1.76 \\
\hline VIII & {$[2 \mathrm{~A}+\mathbf{1}+\mathbf{1}+\mathbf{1}+\mathbf{1}-3 \mathrm{H}]^{+}$} & $\mathrm{C}_{30} \mathrm{H}_{27} \mathrm{~N}_{10} \mathrm{O}_{4}^{+1}$ & 591.2211 & 591.2169 & -7.10 \\
\hline \multicolumn{6}{|c|}{ dGMP } \\
\hline I & {$[\mathrm{G}+\mathrm{H}]^{+}$} & $\mathrm{C}_{5} \mathrm{H}_{6} \mathrm{~N}_{5} \mathrm{O}^{+1}$ & 152.0567 & 152.0581 & +9.21 \\
\hline II & {$[2 \mathrm{G}+\mathrm{H}]^{+}$} & $\mathrm{C}_{10} \mathrm{H}_{11} \mathrm{~N}_{10} \mathrm{O}_{2}^{+1}$ & 303.1061 & 303.1059 & -0.66 \\
\hline \multicolumn{6}{|c|}{ dCMP } \\
\hline I & 1 & $\mathrm{C}_{5} \mathrm{H}_{5} \mathrm{O}^{+1}$ & 81.0335 & 81.0338 & +3.70 \\
\hline II & {$[\mathrm{C}+\mathrm{H}]^{+}$} & $\mathrm{C}_{4} \mathrm{H}_{6} \mathrm{~N}_{3} \mathrm{O}^{+1}$ & 112.0505 & 112.0497 & -7.14 \\
\hline III & {$[\mathrm{C}+\mathbf{1}]^{+}$} & $\mathrm{C}_{9} \mathrm{H}_{10} \mathrm{~N}_{3} \mathrm{O}_{2}^{+1}$ & 192.0768 & 192.0782 & +7.29 \\
\hline IV & {$[\mathrm{C}+\mathbf{1}+\mathbf{1}-\mathrm{H}]^{+}$} & $\mathrm{C}_{14} \mathrm{H}_{14} \mathrm{~N}_{3} \mathrm{O}_{3}^{+1}$ & 272.1030 & 272.1029 & -0.37 \\
\hline V & {$[2 \mathrm{C}+\mathbf{1}]^{+}$} & $\mathrm{C}_{13} \mathrm{H}_{15} \mathrm{~N}_{6} \mathrm{O}_{3}{ }^{+1}$ & 303.1200 & 303.1206 & +1.98 \\
\hline VI & {$[\mathrm{C}+\mathbf{1}+\mathbf{1}+\mathbf{1}-2 \mathrm{H}]^{+}$} & $\mathrm{C}_{19} \mathrm{H}_{18} \mathrm{~N}_{3} \mathrm{O}_{4}{ }^{+1}$ & 352.1292 & 352.1287 & -1.42 \\
\hline VII & {$[2 \mathrm{C}+\mathbf{1}+\mathbf{1}-\mathrm{H}]^{+}$} & $\mathrm{C}_{18} \mathrm{H}_{19} \mathrm{~N}_{6} \mathrm{O}_{4}^{+1}$ & 383.1462 & 383.1451 & -2.87 \\
\hline VIII & {$[\mathrm{C}+\mathbf{1}+\mathbf{1}+\mathbf{1}+\mathbf{1}-3 \mathrm{H}]^{+}$} & $\mathrm{C}_{24} \mathrm{H}_{22} \mathrm{~N}_{3} \mathrm{O}_{5}^{+1}$ & 432.1554 & 432.1520 & -7.87 \\
\hline VIIII & {$[2 \mathrm{C}+\mathbf{1}+\mathbf{1}+\mathbf{1}-2 \mathrm{H}]^{+}$} & $\mathrm{C}_{23} \mathrm{H}_{23} \mathrm{~N}_{6} \mathrm{O}_{5}^{+1}$ & 463.1724 & 463.1696 & -6.05 \\
\hline $\mathrm{X}$ & {$[2 \mathrm{C}+\mathbf{1}+\mathbf{1}+\mathbf{1}+\mathbf{1}-3 \mathrm{H}]^{+}$} & $\mathrm{C}_{28} \mathrm{H}_{27} \mathrm{~N}_{6} \mathrm{O}_{6}^{+1}$ & 543.1987 & 543.1946 & -7.55 \\
\hline \multicolumn{6}{|c|}{ dTMP } \\
\hline I & 1 & $\mathrm{C}_{5} \mathrm{H}_{5} \mathrm{O}^{+1}$ & 81.0335 & 81.0336 & +1.23 \\
\hline II & {$[2+\mathrm{H}]^{+}$} & $\mathrm{C}_{5} \mathrm{H}_{7} \mathrm{O}_{2}^{+1}$ & 99.0441 & 99.0434 & -7.07 \\
\hline III & {$[3+\mathrm{H}]^{+}$} & $\mathrm{C}_{5} \mathrm{H}_{9} \mathrm{O}_{3}{ }^{+1}$ & 117.0546 & 117.0555 & +7.69 \\
\hline IV & {$[\mathrm{T}+\mathrm{H}]^{+}$} & $\mathrm{C}_{5} \mathrm{H}_{7} \mathrm{~N}_{2} \mathrm{O}_{2}^{+1}$ & 127.0502 & 127.0503 & +0.79 \\
\hline V & {$\left[\mathrm{M}-\mathrm{HPO}_{3}+\mathrm{H}\right]^{+}$} & $\mathrm{C}_{10} \mathrm{H}_{15} \mathrm{~N}_{2} \mathrm{O}_{5}^{+1}$ & 243.0976 & 243.0967 & -7.40 \\
\hline VI & {$\left[2 \mathrm{M}-2 \mathrm{HPO}_{3}+\mathrm{H}\right]^{+}$} & $\mathrm{C}_{20} \mathrm{H}_{29} \mathrm{~N}_{4} \mathrm{O}_{10}{ }^{+1}$ & 485.1878 & 485.1886 & +1.65 \\
\hline
\end{tabular}

Figure 2. The DART mass spectra of dAMP, dGMP, dCMP, and dTMP in positive-ion mode. The accurate $\mathrm{m} / \mathrm{z}$ value assignments of ions represented by peaks in these mass spectra are shown in the table. 

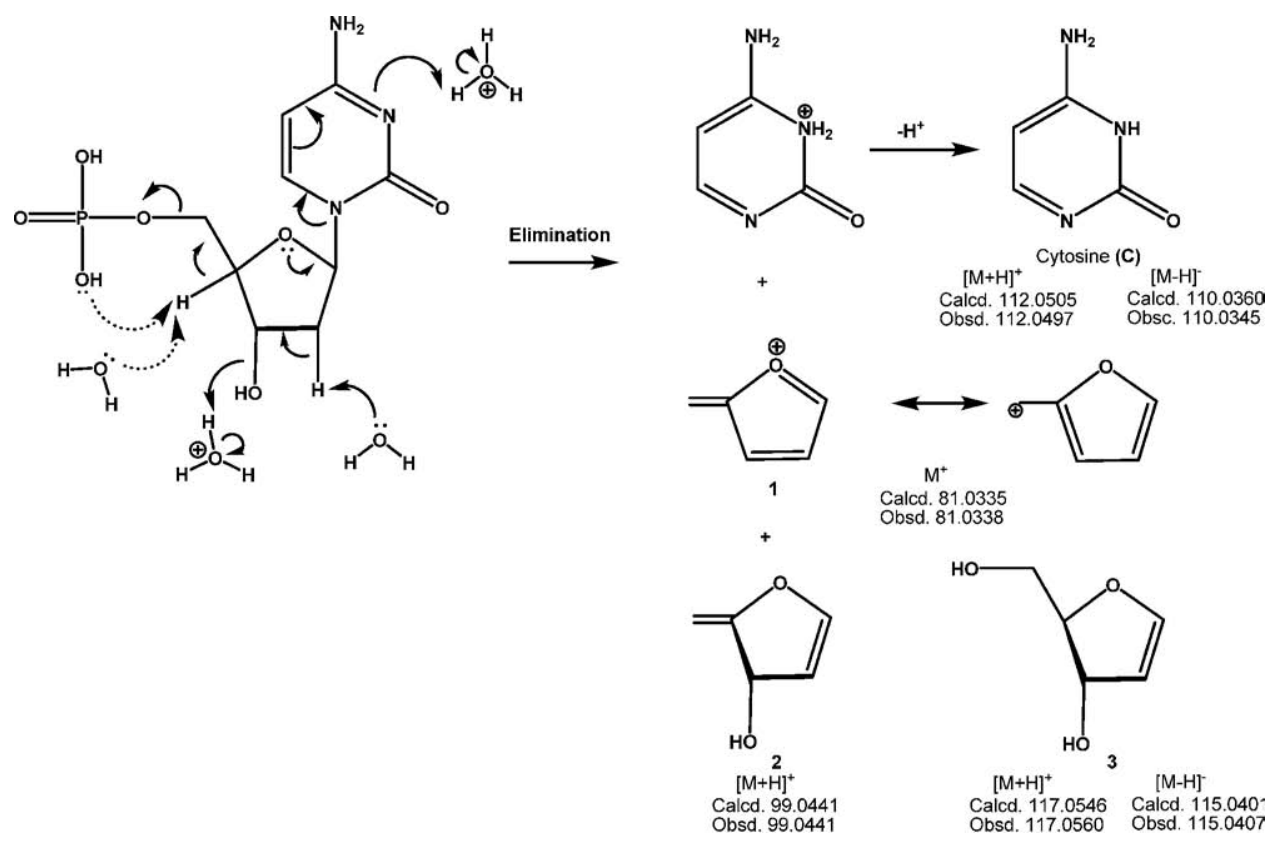

Scheme 1. A plausible mechanism of formation of $\mathbf{1}$ and other elimination products from dCMP.

tions at the $5^{\prime}$ - and $3^{\prime}$-positions and a depyrimidination process as well to yield small fragments including 2-methylene-2H-furanium ion (1), cytosine, and other fragments ( 2 and 3$)$. The elemental composition analysis provides a reasonable formula of $\left[\mathrm{C}_{5} \mathrm{H}_{5} \mathrm{O}\right]^{+}$for this ion with $\mathrm{m} / \mathrm{z} 81.034$, a perfect match of $\mathbf{1}$. Fragment 1 can be stabilized through resonance (Scheme 1), and it was previously reported as a primary ion in the study of 4-substituted N-(2-furylmethyl)anilines using electronionization (EI) mass spectrometry [22]. In contrast to nucleotides, the production of $\mathbf{1}$ was not observed in our experiments of nucleosides (Figure S-2 of the Supporting Information), suggesting that the elimination of $5^{\prime}$-phosphate of nucleotides is crucial to the formation of fragment 1. Removal of the $5^{\prime}$-phosphate group of nucleotides could be facilitated via the intramolecular elimination reaction promoted by the oxygen atom of 5'-phosphate (Scheme 1).

We initially thought that this unique peak pattern resulted from non-covalently bound aggregates in DART mass spectrometry. This assumption was readily tested by simply elevating the potential difference between orifice 1 and orifice 2 in the DART mass spectrometer. Ions accelerated by the raised potential $(65 \mathrm{~V})$ can collide with nitrogen molecules that are present between the two orifices, leading to collisionally activated dissociation (CAD). We believe that the ion representing non-covalently bound aggregates should diminish quickly with increasing the potential because these ions are less stable than covalently bound ions. Our results revealed that when the potential of orifice 1 was increased from 20 to $80 \mathrm{~V}$, the peaks representing 1 became the base peak, and the peaks representing the proposed adduct ions were still present with high intensities (Figure S-4 of the Supporting Information).
This suggests that these ions are relatively stable and are most likely covalently bound.

It is necessary to point out that $\mathbf{1}$ could be produced as a result of pyrolytic processes. The temperature of helium gas used in the DART ion source was 200 or $250{ }^{\circ} \mathrm{C}$, a temperature that is suitable for pyrolysis of nucleotides [23]. Pyrolysis of analytes at a sufficiently high-temperature in DART mass spectrometry has been previously reported [24, 25]. In our experiments, with the elevation of the helium stream temperature from 200 to $250{ }^{\circ} \mathrm{C}$, the production of $\mathbf{1}$ increased significantly, indicating that such fragmentation was indeed temperature-dependent. Separate experiments were carried out by heating dAMP or dCMP in a vacuumsealed glass vial at $220^{\circ} \mathrm{C}$ for $5 \mathrm{~min}$ followed by measuring the analytes using the electrospray ion source of the AccuTOF mass spectrometer that has a relatively low-temperature ionization source and thus can avoid further pyrolysis of the analytes. The mass spectra of dAMP and dCMP obtained using electrospray mass spectrometry (Figure S-5 of the Supporting Information) are very similar to those obtained with DART mass spectrometry, suggesting that the formation of $\mathbf{1}$ may involve pyrolytic processes. However, this conclusion does not conflict with our proposed mechanisms because elimination reactions are commonly observed under pyrolytic conditions [23]. Wiebers and Shapiro reported elimination reactions at the $5^{\prime}$ - and $3^{\prime}$-positions of nucleotides under pyrolytic conditions using electron-ionization (EI) mass spectrometry [26]. Such eliminations were also observed in the fragmentation analysis of DNA using pyrolysis field desorption mass spectrometry [27]. Interestingly, the production of 1 in our DART experiment of dGMP was not detected under the same conditions. This observation is probably 
attributed to the fact that dGMP has lower vapor pressure than the other three nucleotides [28], making the fragmentation of dGMP occur at higher temperatures $\left(>250^{\circ} \mathrm{C}\right)$. The open-air condition of the DART ion source should also facilitate the elimination reactions because water can act as a base and as a proton source (Scheme 1).

Our direct observation of fragment $\mathbf{1}$ adds another example to the previous research in this field. In our literature search for pyrolysis of DNA (mostly published in the 1970s and the 1980s), we found out that very few groups reported the observation of the furantype fragments with $m / z 81$ partially due to the mass range used (above $m / z$ 100) [26, 29]. In addition, the proposed structures for this fragment in the published papers were somewhat contradictory. A peak at $m / z 81$ in the EI spectrum of dAMP was assigned as representing a fragment of adenine with two sequential losses of HCN; however, this fragmentation pathway can not be used to explain the peaks at $m / z 81$ observed in the spectra of dTMP and dGMP within the same publication [30]. A methylfuran radical cation $\left(\left[\mathrm{C}_{5} \mathrm{H}_{6} \mathrm{O}\right]^{+} \cdot, m / z\right.$ 82), other than $\mathbf{1}$, was reported in the pyrolysis mass spectrometry of silylated deoxyadenosine 5'-monophosphate [23]. A comparison of our results with those of others suggests that the structures of furan-type fragments produced via pyrolytic processes are probably condition dependent.

According to the elemental composition based on accurate $m / z$ values, the consecutive peaks with an increment of $80 \mathrm{~m} / \mathrm{z}$ units are clearly associated with fragment 1. Schulten and Beckey reported a similar observation to ours. In their studies, the multiply substituted bases were chemically bound to dehydrated deoxyribose (methylfuran) followed by loss of a hydrogen atom in the pyrolysis field desorption mass spectrometry of deoxyribonucleic acid. The actual structures of their adducts were not determined [27]. In our experiments, the ratio of 1 to nucleobase ranges from 0 to 4 . The intensity of the peaks representing adduct ions decreases gradually with increasing ratios. Two plausible reaction mechanisms (Scheme 2) are proposed to

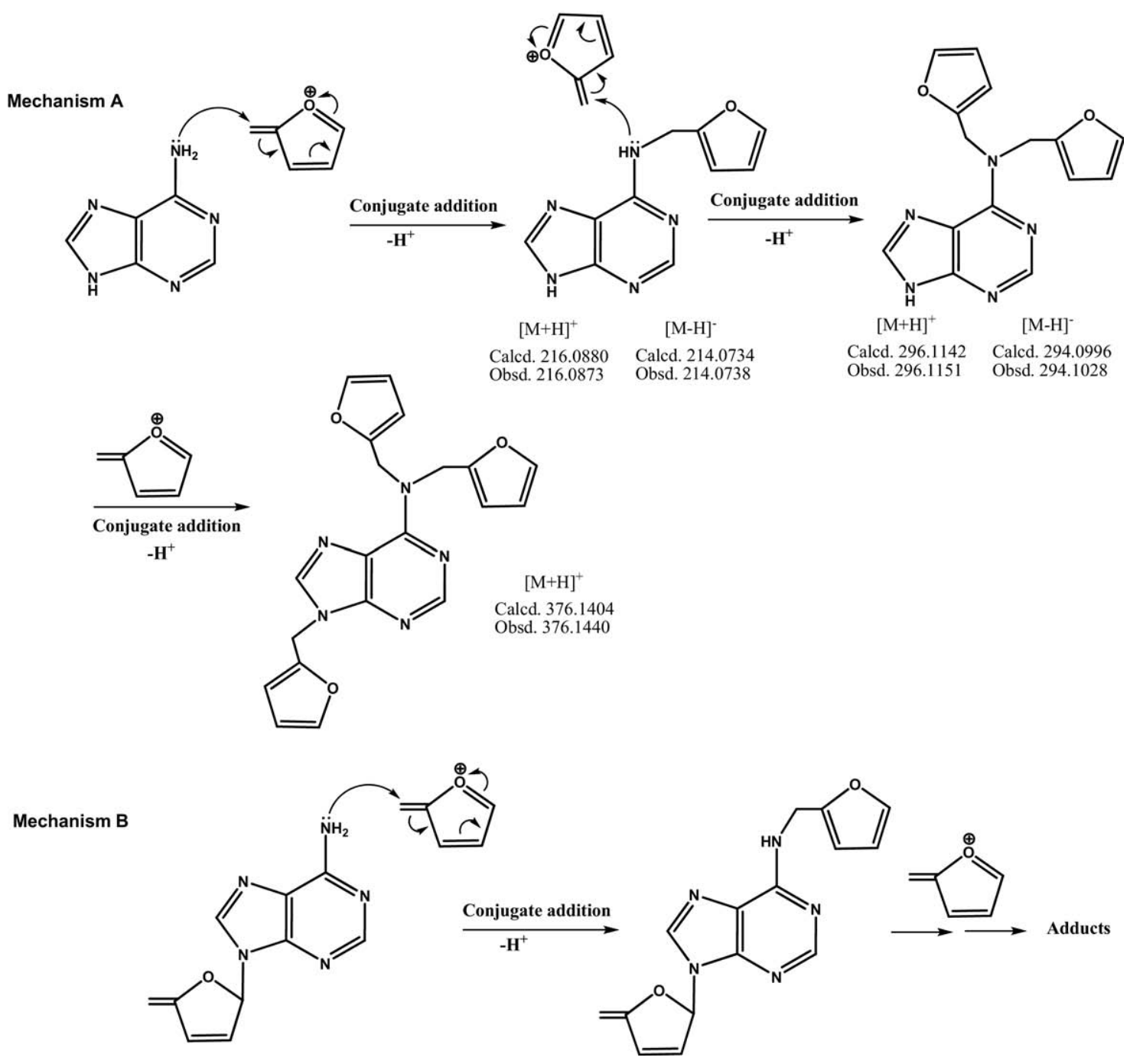

Scheme 2. Two plausible mechanisms of formation of adducts in the experiment of dAMP. 
explain the observations where the accurate mass values have typical errors of less than $10 \mathrm{ppm}$. In the first mechanism, $\mathbf{1}$ is susceptible to conjugate addition with nucleobases in the DART ion source to form covalentlylinked stable adducts (Scheme 2, Mechanism A). The multiple nucleophilic sites (i.e., exocyclic amino groups) present in adenine and cytosine form adducts with several equivalents of $\mathbf{1}$, generating the peak pattern with an increment of $80 \mathrm{~m} / \mathrm{z}$ units (Figure 2). The second mechanism (Scheme 2, Mechanism B) suggests that the adduct formation originates from the fragments that are produced by eliminating the 5 '- and 3 '- moieties from nucleotides without the loss of nucleobases. The exocyclic amines in nucleobases of these fragments can react with 1 to form the corresponding adducts. A commonality of these two mechanisms is the conjugate addition of $\mathbf{1}$ to exocyclic amino groups of nucleobases. Evidence to support this conclusion comes from the observation that the corresponding peak pattern with an increment of $80 \mathrm{~m} / \mathrm{z}$ units is not detected in the case of dTMP, which does not contain exocyclic amino groups on its nucleobase. Our observation is also consistent with a previous report that unlike other nucleobases, thymine and uracil could not form adducts with a $\mathrm{PO}_{3}$ moiety because of the lack of an exocyclic nitrogen [26]. Interestingly, the addition reactions between several equivalents of $\mathbf{1}$ and two nucleobases (adenine and cytosine) were also detected. Under the DART mass spectrometry conditions, possibly the exocyclic amino groups of adenine and cytosine can undergo an addition reaction with another nucleobase. A plausible mechanism is outlined in Scheme S-1 of the Supporting Information.

The validation of the first mechanism (Scheme 2, Mechanism A) was established via the following experiment. A homogenous mixture (1:1 molar ratio) of dAMP and ${ }^{13} \mathrm{C},{ }^{15} \mathrm{~N}$-labeled dAMP was introduced into the DART mass spectrometer under the same conditions as described above. The addition products resulting from the recombination between ${ }^{13} \mathrm{C},{ }^{15} \mathrm{~N}$-labeled and non-isotope labeled fragments was detected. $\mathrm{Ob}-$ served accurate $m / z$ values, along with theoretical values, of ions and their relationships with the corresponding elemental compositions are listed in Figure 3. In particular, the ion with $\mathrm{m} / \mathrm{z} 221.1048$ represents the adduct formed between non-isotope labeled adenine (A) and ${ }^{13} \mathrm{C}_{1}^{15} \mathrm{~N}$-labeled fragment $\mathbf{1}\left(\mathbf{1}^{\text {iso }}\right)$ and the ion with $\mathrm{m} / \mathrm{z} 226.0899$ represents the adduct formed between ${ }^{13} \mathrm{C}_{1}^{15} \mathrm{~N}$-labeled adenine $\left(\mathrm{A}^{\text {iso }}\right.$ ) and $\mathbf{1}$ (For the adduct structures, see Scheme S-2 of the Supporting Information). The observation of these two peaks clearly indicates that nucleobases in the DART ion source directly react with fragment 1, validating the first reaction mechanism. The addition reaction between a nucleobase and $\mathbf{1}$ was also confirmed by the spectrum obtained using DART mass spectrometry of a mixture of dAMP and ${ }^{13} \mathrm{C}_{1}^{15} \mathrm{~N}$-labeled dTMP (1:1 molar ratio) (Figure S-6 of the Supporting Information). The ion with $\mathrm{m} / \mathrm{z} 221.1040$ represents the adduct (Scheme S-3 of the Supporting Information) between adenine that results from the fragmentation of $\mathrm{dAMP}$ and $\mathbf{1}^{\text {iso }}$ that is produced from ${ }^{13} \mathrm{C},{ }^{15} \mathrm{~N}$-labeled dTMP. In this study, we were not able to determine whether the adduct formation occurs according to the second proposed mechanism (Scheme 2, Mechanism B) although such reactions are definitely possible. It is also necessary to point out that the actual addition positions of $\mathbf{1}$ to nucleobases in the above proposed mechanisms remain unknown because analysis of the accurate $m / z$ values of the adduct ions alone is not enough to deduce the isomeric structures. To our knowledge, the production of $\mathbf{1}$ and its corresponding adducts with nucleobases in DART mass spectrometry has not been previously reported.

We are aware of the possibility that the above described adducts could result from reactions with radicals under pyrolytic conditions; however, our experimental results and conditions suggest that the formation of the adducts is not likely to involve radical processes. The elemental composition of $\left[\mathrm{C}_{5} \mathrm{H}_{5} \mathrm{O}\right]^{+}$represents an even-electron species [31]. The mass spectra shown in Figure 2 have far fewer peaks than those normally obtained in radical reactions. In addition, the open-air conditions of the DART ion source in positiveion mode would produce a significant amount of oxygen adducts if the mechanism did indeed involve radicals. Direct support for our conclusion comes from a DART result obtained by combining nucleotides with a radical scavenger (cysteine) in a 1:1 molar ratio. Cysteine quenches radicals and thus would dramatically affect the fragment pattern if the adduct formation were to involve a radical process. In our experiments, the presence of cysteine apparently does not alter the fragment patterns of nucleotides (Figure S-7 of the Supporting Information), suggesting that the adduct formation is unlikely to involve radicals.

Further evidence for the formation of $\mathbf{1}$ in DART mass spectrometry arises from the observation of the adduct formation between $\mathbf{1}$ and several nucleophiles including 1,2-diaminoethane (4), 2-aminoethanol (5), and 1,6-diaminohexane (6) as models when each individual nucleophile was introduced into the DART ionization source simultaneously with dCMP (Figure 4). Compound 5 resulted in the most distinct peak at $\mathrm{m} / \mathrm{z}$ 142.0865, representing the adduct formation between 5 and 1. Compounds 4 and 6 containing diamino groups yielded less abundant yet observable adduct ions with $m / z 141.1034$ and 197.1657, respectively. The average $\mathrm{m} / \mathrm{z}$ value errors in our measurements were less than 10 ppm. These observations suggest that the adduct formation of $\mathbf{1}$ is nucleophile dependent and most likely results from conjugate additions (Scheme S-4 of the Supporting Information). It is also noteworthy that the model amines and nucleotides were introduced into the DART ionization source without physically mixing them together; therefore, the addition reactions appeared to take place in the gas-phase. The adduct formation in the gas-phase was also confirmed by simultaneously introducing dTMP and adenine into the DART ion source using two separate melting point 


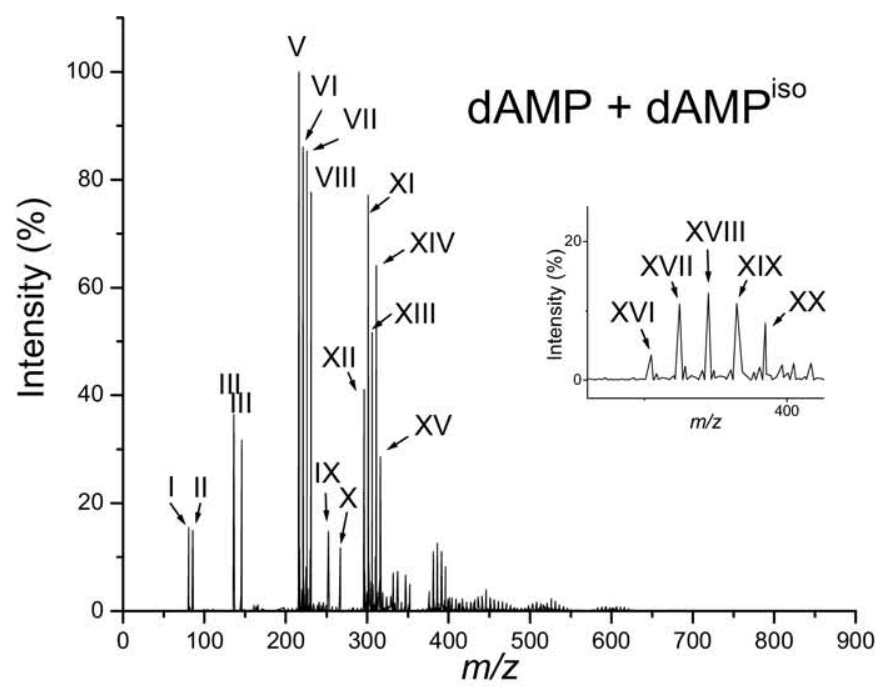

\begin{tabular}{|c|c|c|c|c|c|}
\hline Ion No. & Ion Assignment & Formula & Calculated & Observed & $\begin{array}{l}\text { Error } \\
\text { (ppm) }\end{array}$ \\
\hline \multicolumn{6}{|c|}{ dAMP $+{ }^{13} \mathrm{C},{ }^{15} \mathrm{~N}-\mathrm{dAMP}\left(\mathrm{dAMP}{ }^{\mathrm{iso}}\right)$} \\
\hline I & 1 & $\mathrm{C}_{5} \mathrm{H}_{5} \mathrm{O}^{+1}$ & 81.0335 & 81.0337 & +2.47 \\
\hline II & $1^{\text {iso }}$ & ${ }^{13} \mathrm{C}_{5} \mathrm{H}_{5} \mathrm{O}^{+1}$ & 86.0503 & 86.0499 & -4.65 \\
\hline III & {$[\mathrm{A}+\mathrm{H}]^{+}$} & $\mathrm{C}_{5} \mathrm{H}_{6} \mathrm{~N}_{5}^{+1}$ & 136.0618 & 136.0606 & -8.82 \\
\hline IV & {$\left[\mathrm{A}^{\text {iso }}+\mathrm{H}\right]^{+}$} & ${ }^{13} \mathrm{C}_{5} \mathrm{H}_{6}{ }^{15} \mathrm{~N}_{5}{ }^{+1}$ & 146.0637 & 146.0633 & -2.74 \\
\hline $\mathrm{V}$ & {$[\mathrm{A}+\mathbf{1}]^{+}$} & $\mathrm{C}_{10} \mathrm{H}_{10} \mathrm{~N}_{5} \mathrm{O}^{+1}$ & 216.0880 & 216.0861 & -8.79 \\
\hline VI & {$\left[\mathrm{A}+\mathbf{1}^{\text {iso }}\right]^{+}$} & $\mathrm{C}_{5}{ }^{13} \mathrm{C}_{5} \mathrm{H}_{10} \mathrm{~N}_{5} \mathrm{O}^{+1}$ & 221.1048 & 221.1009 & -17.6 \\
\hline VII & {$\left[\mathrm{A}^{\text {iso }}+\mathbf{1}\right]^{+}$} & $\mathrm{C}_{5}{ }^{13} \mathrm{C}_{5} \mathrm{H}_{10}{ }^{15} \mathrm{~N}_{5} \mathrm{O}^{+1}$ & 226.0899 & 226.0871 & -12.4 \\
\hline VIII & {$\left[\mathrm{A}^{\text {iso }}+\mathbf{1}^{\text {iso }}\right]^{+}$} & ${ }^{13} \mathrm{C}_{10} \mathrm{H}_{10}{ }^{15} \mathrm{~N}_{5} \mathrm{O}^{+1}$ & 231.1067 & 231.1039 & -12.1 \\
\hline IX & {$\left[\mathrm{dAMP}-\mathrm{HPO}_{3}+\mathrm{H}\right]^{+}$} & $\mathrm{C}_{10} \mathrm{H}_{14} \mathrm{~N}_{5} \mathrm{O}_{3}^{+1}$ & 252.1091 & 252.1069 & -8.73 \\
\hline $\mathrm{X}$ & {$\left[\mathrm{dAMP}^{\text {iso }}-\mathrm{HPO}_{3}+\mathrm{H}\right]^{+}$} & ${ }^{13} \mathrm{C}_{10} \mathrm{H}_{14}{ }^{15} \mathrm{~N}_{5} \mathrm{O}_{3}{ }^{+1}$ & 267.1278 & 267.1278 & +0.00 \\
\hline XI & {$[\mathrm{A}+\mathbf{1}+\mathbf{1}-\mathrm{H}]^{+}$} & $\mathrm{C}_{15} \mathrm{H}_{14} \mathrm{~N}_{5} \mathrm{O}_{2}^{+1}$ & 296.1142 & 296.1139 & -1.01 \\
\hline XII & {$\left[\mathrm{A}+\mathbf{1}+\mathbf{1}^{\text {iso }}-\mathrm{H}\right]^{+}$} & $\mathrm{C}_{10}{ }^{13} \mathrm{C}_{5} \mathrm{H}_{14} \mathrm{~N}_{5} \mathrm{O}_{2}^{+1}$ & 301.1310 & 301.1317 & +2.32 \\
\hline XIII & {$\left[\mathrm{A}+\mathbf{1}^{\text {iso }}+\mathbf{1}^{\text {iso }}-\mathrm{H}\right]^{+}$} & $\mathrm{C}_{5}{ }^{13} \mathrm{C}_{10} \mathrm{H}_{14} \mathrm{~N}_{5} \mathrm{O}_{2}^{+1}$ & 306.1477 & 306.1318 & -51.9 \\
\hline XIV & {$\left[\mathrm{A}^{\text {iso }}+\mathbf{1}+\mathbf{1}^{\text {iso }}-\mathrm{H}\right]^{+}$} & $\mathrm{C}_{5}{ }^{13} \mathrm{C}_{10} \mathrm{H}_{14}{ }^{15} \mathrm{~N}_{5} \mathrm{O}_{2}^{+1}$ & 311.1329 & 311.1345 & +5.14 \\
\hline XV & {$\left[\mathrm{A}^{\text {iso }}+\mathbf{1}^{\text {iso }}+\mathbf{1}^{\text {iso }}-\mathrm{H}\right]^{+}$} & ${ }^{13} \mathrm{C}_{15} \mathrm{H}_{14}{ }^{15} \mathrm{~N}_{5} \mathrm{O}_{2}{ }^{+1}$ & 316.1497 & 316.1505 & +2.53 \\
\hline XVI & {$[\mathrm{A}+\mathbf{1}+\mathbf{1}+\mathbf{1}-2 \mathrm{H}]^{+}$} & $\mathrm{C}_{20} \mathrm{H}_{18} \mathrm{~N}_{5} \mathrm{O}_{3}^{+1}$ & 376.1404 & 376.1467 & +16.8 \\
\hline XVII & {$\left[\mathrm{A}+\mathbf{1}+\mathbf{1}+\mathbf{1}^{\text {iso }}-2 \mathrm{H}\right]^{+}$} & $\mathrm{C}_{15}{ }^{13} \mathrm{C}_{5} \mathrm{H}_{18} \mathrm{~N}_{5} \mathrm{O}_{3}{ }^{+1}$ & 381.1572 & 381.1612 & +10.5 \\
\hline XVIII & {$\left[\mathrm{A}+\mathbf{1}+\mathbf{1}^{\text {iso }}+\mathbf{1}^{\text {iso }}-2 \mathrm{H}\right]^{+}$} & $\mathrm{C}_{10}{ }^{13} \mathrm{C}_{10} \mathrm{H}_{18} \mathrm{~N}_{5} \mathrm{O}_{3}^{+1}$ & 386.1740 & 386.1704 & -9.32 \\
\hline XIX & {$\left[\mathrm{A}^{\text {iso }}+\mathbf{1}+\mathbf{1}+\mathbf{1}^{\text {iso }}-2 \mathrm{H}\right]^{+}$} & $\mathrm{C}_{10}{ }^{13} \mathrm{C}_{10} \mathrm{H}_{18}{ }^{15} \mathrm{~N}_{5} \mathrm{O}_{3}{ }^{+1}$ & 391.1591 & 391.1658 & +17.1 \\
\hline XX & {$\left[\mathrm{A}^{\text {iso }}+\mathbf{1}+\mathbf{1}^{\text {iso }}+\mathbf{1}^{\text {iso }}-2 \mathrm{H}\right]^{+}$} & $\mathrm{C}_{5}{ }^{13} \mathrm{C}_{15} \mathrm{H}_{18}{ }^{15} \mathrm{~N}_{5} \mathrm{O}_{3}{ }^{+1}$ & 396.1759 & 396.1762 & +0.76 \\
\hline
\end{tabular}

Figure 3. The DART mass spectrum of dAMP mixed with ${ }^{13} \mathrm{C},{ }^{15} \mathrm{~N}-\mathrm{dAMP}$ (1:1 molar ratio) in positive-ion mode. The accurate $\mathrm{m} / \mathrm{z}$ value assignment of ions represented by peaks in the mass spectrum is shown in the table.

capillary tubes. The ion with $\mathrm{m} / \mathrm{z} 216.0867$ representing the adduct formed between 1 and adenine was detected with a large abundance (Figure S-8 of the Supporting Information). Note that fragment $\mathbf{1}$ in this experiment could only be produced from the decomposition of dTMP, and adenine is introduced into the DART ion source separately from dTMP, suggesting that the ion with $\mathrm{m} / \mathrm{z} 216.0867$ is formed in the gas-phase. The observation of this particular ion also validates the first proposed mechanism that reactions between fragment 1 and nucleobases are possible. Interestingly, the ions representing the adduct ion formed with several equiv- 

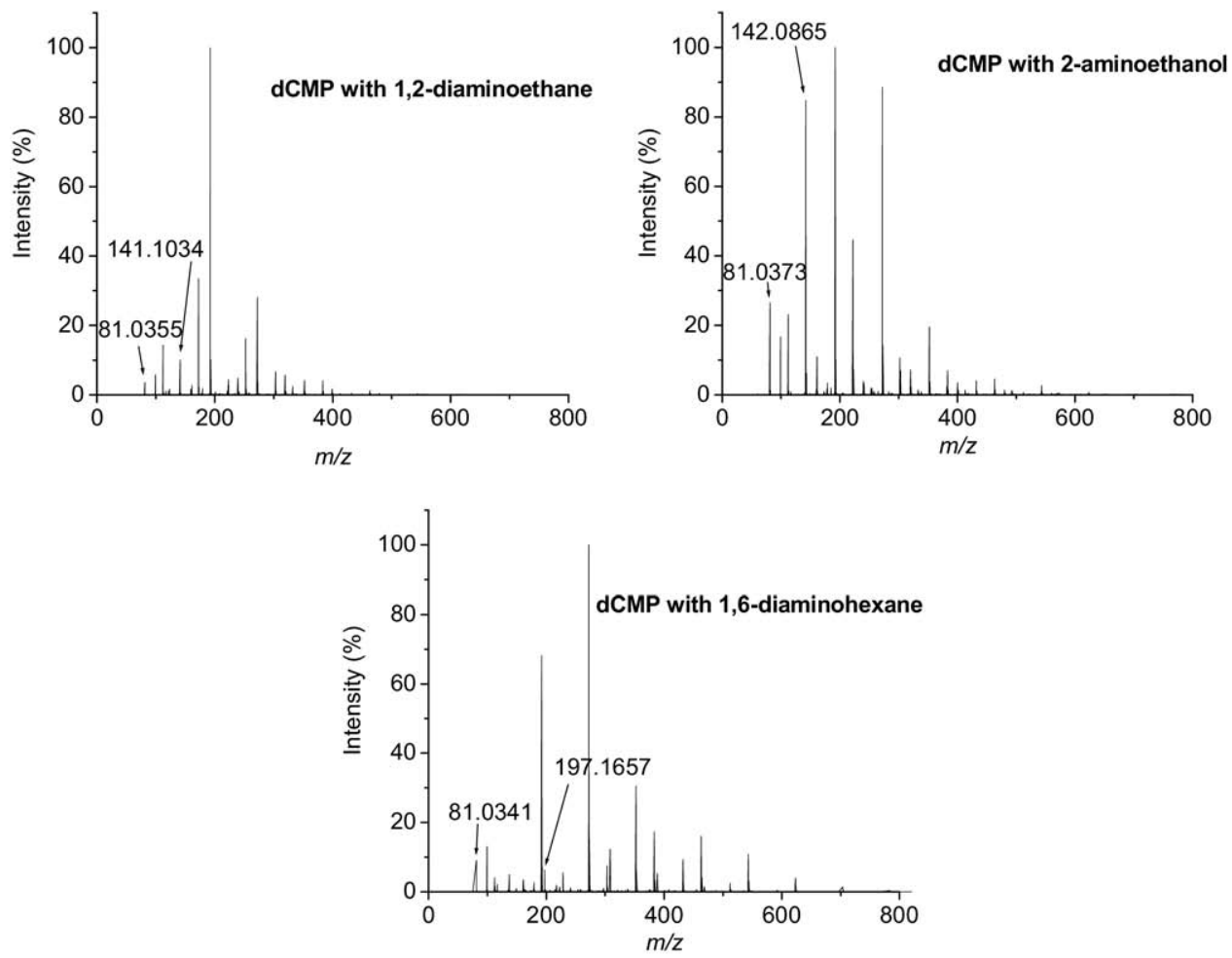

\begin{tabular}{llccc}
\hline Nucleophile $(\mathrm{M})$ & Formula $(\mathrm{M}+80)^{+}$ & Calculated & Observed & Error (ppm) \\
\hline 1,2-diaminoethane & $\mathrm{C}_{7} \mathrm{H}_{13} \mathrm{~N}_{2} \mathrm{O}^{+1}$ & 141.1022 & 141.1031 & +6.38 \\
2-aminoethanol & $\mathrm{C}_{7} \mathrm{H}_{12} \mathrm{NO}_{2}{ }^{+1}$ & 142.0863 & 142.0865 & +1.41 \\
1,6-diaminohexane & $\mathrm{C}_{11} \mathrm{H}_{21} \mathrm{~N}_{2} \mathrm{O}^{+1}$ & 197.1648 & 197.1657 & +4.56 \\
\hline
\end{tabular}

Figure 4. The DART mass spectra of dCMP with the model amines in positive-ion mode. The assignment of ions peaks representing the adducts formed between $\mathbf{1}$ and a corresponding model amine is shown in the table.

alents of $\mathbf{1}$ and adenine were not observable in this experiment (Figure S-8 of the Supporting Information). We believe that the volatility of adenine is better than dTMP in the DART ionization source. Therefore, the concentration of adenine in the gas-phase is much higher than that of $\mathbf{1}$, leading to the formation of one major type of adduct ion (a single hit condition).

\section{Fragmentation of Nucleotides in Negative-Ion Mode}

Nucleotides were analyzed by the DART mass spectrometer in negative-ion mode. The behaviors of nucleotides in negative-ion mode are similar to those in positive-ion mode. No ions representing the intact nucleotides or the corresponding oxygen adducts, as expected in negative-ion mode, were observed. Only peaks representing the fragment ions of nucleotides were detected, indicating that the conditions used in negative-ion mode can break down the nucleotides. The fragmentation of nucleotides in negative-ion mode may also be due to a pyrolytic process resulting from the temperature of the helium stream. The high resolving power and accurate $\mathrm{m} / \mathrm{z}$ capability of the DART mass spectrometer allow the elemental compositions of most of the fragment ions in these spectra to be unambiguously identified. Detailed accurate $\mathrm{m} / \mathrm{z}$ values of ions and their relationships with the corresponding elemental compositions are listed in Figure S-9 of the Supporting Information. For instance, the ion with $\mathrm{m} / \mathrm{z}$ 96.9695 represents the $\left[\mathrm{H}_{2} \mathrm{PO}_{4}\right]^{-}$anion, the ion with $\mathrm{m} / \mathrm{z} 99.0440$ represents an anion of 2 , and the ion with $\mathrm{m} / \mathrm{z} 115.0403$ represents a deoxyribose anion of 3 (these are defined by the elemental composition analysis, Scheme 1). The loss of a nucleobase must be one of the fragmentation steps because the peaks representing the anion of adenine, cytosine, and thymine were clearly observed in the corresponding mass spectra (Figure S-9 of the Supporting Information). dGMP behaved differently from other three nucleotides because no peaks of significant intensity were detected in the dGMP spectrum even when it was subjected to the DART mass spectrometer at a higher temperature $\left(280^{\circ} \mathrm{C}\right)$. A previous report on decompositions of multiply charged oligonucleotide anions [32] revealed the order of preference to lose a base is dAMP, dTMP $>$ dCMP $>>$ dGMP, which is consistent with our observation. More importantly, the spectra of dAMP and dCMP show the 
same consecutive peak pattern with an increment of 80 $\mathrm{m} / \mathrm{z}$ units as observed in the positive-ion mode for these two nucleotides (Figure S-9 of the Supporting Information). The $80 \mathrm{~m} / \mathrm{z}$ unit increment supports the formation of $\mathbf{1}$ even though 1 cannot be observed in negative-ion mode. All the observed fragment ions have a reasonably high abundance, indicating that the ions are relatively stable and are major ions produced during the decomposition of dAMP and dCMP in the DART mass spectrometer. Notably, such a peak pattern does not exist in the spectrum of dTMP because the lack of exocyclic amines prohibits it from reacting with $\mathbf{1}$.

\section{Conclusions}

Our results show that nucleotides and nucleosides behave differently in the DART ion source. Due to their 5 '-monophosphate group, nucleotides in the DART ion source undergo multiple-elimination reactions to yield $\mathbf{1}$ $\left(\left[\mathrm{C}_{5} \mathrm{H}_{5} \mathrm{O}\right]^{+}\right)$, which can be detected in positive-ion mode. In contrast to nucleotides, nucleosides also fragment in the DART ion source; however, $\mathbf{1}$ is not produced. To the best of our knowledge, this fragment $\mathbf{1}$ arising from the decomposition of 2'-deoxynucleotides has never been observed in DART mass spectrometry before. In addition, fragment 1 reacts with nucleophiles (nucleobases or amines) present in the DART ion source to yield adducts with a distinctive pattern $(80 \mathrm{~m} / \mathrm{z}$ unit increment), suggesting that the condition of the DART ion source may be suitable for future investigation of in-source reactions between analytes. Our observations also suggest that the conditions of the DART ion source should be taken into consideration when utilizing the DART mass spectrometer to analyze samples with unique structures. The limit of detection of nucleotides and nucleosides and the behavior of synthetic and native DNA and RNA in DART mass spectrometry will be investigated in due course.

\section{Acknowledgments}

The authors are grateful for support of this research from the University of the Pacific and for the use of the Pacific Mass Spectrometry Facility. They also thank Dr. Andreas H. Franz for helpful suggestions.

\section{Appendix A Supplementary Material}

Supplementary material associated with this article may be found in the online version at doi:10.1016/ j.jasms.2010.03.046.

\section{References}

1. Malins, D. C.; Hellstrom, K. E.; Anderson, K. M.; Johnson, P. M.; Vinson, M. A. Antioxidant-Induced Changes in Oxidized DNA. Proc. Natl. Acad. Sci. U.S.A. 2002, 99, 5937-5941.

2. Kamiya, H. Mutagenic Potentials of Damaged Nucleic Acids Produced by Reactive Oxygen/Nitrogen Species: Approaches Using Synthetic Oligonucleotides and Nucleotides. Nucleic Acids Res. 2003, 31, 517-531.
3. Richter, C.; Park, J.-W.; Ames, B. N. Normal Oxidative Damage to Mitochondrial and Nuclear DNA Is Extensive. Proc. Natl. Acad. Sci. U.S.A. 1988, 85, 6465-6467.

4. Newton, R. P.; Kingston, E. E.; Overton, A. Mass Spectrometric Identification of Cyclic Nucleotides Released by the Bacterium Corynebacterium Murisepticum into the Culture Medium. Rapid Commun. Mass Spectrom. 1998, 12, 729-735.

5. Neeley, W. L.; Essigmann, J. M. Mechanisms of Formation, Genotoxicity, and Mutation of Guanine Oxidation Products. Chem. Res. Toxicol. 2006, 19, 491-505.

6. Collins, A. R.; Cadet, J.; Moeller, L.; Poulsen, H. E.; Vina, J. Are We Sure We Know How to Measure 8-Oxo-7,8-Dihydroguanine in DNA from Human Cells? Arch. Biochem. Biophys. 2004, 423, 57-65.

7. Cadet, J.; D'Ham, C.; Douki, T.; Pouget, J. P.; Ravanat, J. L.; Sauvaigo, S. Facts and Artifacts in the Measurement of Oxidative Base Damage to DNA. Free Radical Res. 1998, 29, 541-550.

8. Dizdaroglu, M.; Jaruga, P.; Rodriguez, H. Oxidative Damage to DNA: Mechanisms of Product Formation and Measurement by Mass Spectrometric Techniques. Crit. Rev. Oxidative Stress Aging 2003, 1, 165-189.

9. Holzl, G.; Herbert, O.; Pitsch, S.; Stutz, A.; Huber, C. G. Analysis of Biological and Synthetic Ribonucleic Acids by Liquid ChromatographyMass Spectrometry Using Monolithic Capillary Columns. Anal. Chem. 2005, 77, 673-680.

10. Koc, H.; Swenberg, J. A. Applications of Mass Spectrometry for Quantitation of DNA Adducts. J. Chromatogr. B. 2002, 778, 323-343.

11. Cody, R. B.; Laramee, J. A.; Durst, H. D. Versatile New Ion Source for the Analysis of Materials in Open Air under Ambient Conditions. Anal. Chem. 2005, 77, 2297-2302.

12. Cody, R. B. Observation of Molecular Ions and Analysis of Nonpolar Compounds with the Direct Analysis in Real Time Ion Source. Anal. Chem. 2009, 81, 1101-1107.

13. McEwen, C. N.; Larsen, B. S. Ionization Mechanisms Related to Negative Ion APPI, APCI, and Dart. J. Am. Soc. Mass Spectrom. 2009, 20, 1518-1521.

14. Song, L.; Dykstra, A. B.; Yao, H.; Bartmess, J. E. Ionization Mechanism of Negative Ion-Direct Analysis in Real Time: A Comparative Study with Negative Ion-Atmospheric Pressure Photoionization. J. Am. Soc. Mass Spectrom. 2009, 20, 42-50.

15. Williams, J. P. Patel, V. J. Holland, R. Scrivens, J. H. The Use of Recently Described Ionization Techniques for the Rapid Analysis of Some Common Drugs and Samples of Biological Origin. Rapid Commun. Mass Spectrom. 2006, 20, 1447-1456.

16. Vail, T. M.; Jones, P. R.; Sparkman, O. D. Rapid and Unambiguous Identification of Melamine in Contaminated Pet Food Based on Mass Spectrometry with Four Degrees of Confirmation. J. Anal. Toxicol. 2007, 31, 304-312.

17. Morlock, G.; Schwack, W. Determination of Isopropythioxanthone (ITX) in Milk, Yoghurt and Fat by HPTLC-FLD, HPTLC-ESI/MS, and HPTLC-DART/MS. Anal. Bioanal. Chem. 2006, 385, 586-595.

18. Haefliger, O. P.; Jeckelmann, N. Direct Mass Spectrometric Analysis of Flavors and Fragrances in Real Applications Using Dart. Rapid Commun. Mass Spectrom. 2007, 21, 1361-1366.

19. Borges, D. L. G.; Sturgeon, R. E.; Welz, B.; Curtius, A. J.; Mester, Z Ambient Mass Spectrometric Detection of Organometallic Compounds Using Direct Analysis in Real Time. Anal. Chem. 2009, 81, 9834-9839.

20. Nilles, J. M.; Connell, T. R.; Durst, H. D. Quantitation of Chemical Warfare Agents Using the Direct Analysis in Real Time (Dart) Technique. Anal. Chem. 2009, 81, 6744-6749.

21. Kpegba, K.; Spadaro, T.; Cody, R. B.; Nesnas, N.; Olson, J. A. Analysis of Self-Assembled Monolayers on Gold Surfaces Using Direct Analysis in Real Time Mass Spectrometry. Anal. Chem. 2007, 79, 5479-5483.

22. Solano, E.; Stashenko, E.; Martinez, J.; Mora, U.; Kouznetsov, V. Ion $\left[\mathrm{C}_{5} \mathrm{~h}_{5} \mathrm{O}\right]^{+}$Formation in the Electron-Impact Mass Spectra of 4-SubstitutedN-(2-Furylmethyl)Anilines. Relative Abundance Prediction Ability of the Dft Calulations. J. Mol. Struct. THEOCHEM 2006, 769, 83-85.

23. Moldoveanu, S. C. Analytical Pyrolysis of Natural Organic Polymers; Elsevier: New York, 1998; pp 399-407.

24. Laramee, J. A.; Cody, R. B.; Nilles, J. M.; Durst, H. D. Forensic Applications of DART (Direct Analysis in Real Time) Mass Spectrometry. In Forensic Analysis on the Cutting Edge; John Wiley and Sons, Inc.: Hoboken, NJ, 2007; pp 175-195.

25. Maleknia, S. D.; Vail, T. M.; Cody, R. B.; Sparkman, O. D.; Bell, T. L.; Adams, M. A. Temperature-Dependent Release of Volatile Organic Compounds of Eucalypts by Direct Analysis in Real Time (Dart) Mass Spectrometry. Rapid Commun. Mass Spectrom. 2009, 23, 2241-2246.

26. Wiebers, J. L.; Shapiro, J. A. Sequence Analysis of Oligodeoxyribonucleotides by Mass Spectrometry. 1. Dinucleotide Monophosphates. Biochemistry 1977, 16, 1044-1050.

27. Schulten, H.-R.; Beckey, H. D. Pyrolysis Field Desorption Mass Spectrometry of Deoxyribonucleic Acid. Anal. Chem. 1973, 45, 2358-2362.

28. Gross, M. L.; Lyon, P. A.; Dasgupta, A.; Gupta, N. K. Mass Spectral Studies of Probe Pyrolysis Products of Intact Oligoribonucleotides. Nucleic Acids Res. 1978, 5, 2695-2704.

29. Wiebers, J. L. Detection and Identification of Minor Nucleotides in Intact Deoxyribonucleic Acids by Mass Spectrometry. Nucleic Acids Res. 1976, 3, 2959-2970.

30. Abbas-Hawks, C.; Woorhees, K. J. In Situ Methylation of Nucleic Acids Using Pyrolysis/Mass Spectrometry. Rapid Commun. Mass Spectrom. 1996 10, 1802-1806. 
31. Watson, J. T.; Sparkman, O. D. Introduction to Mass Spectrometry: Instrumentation, Applications, and Strategies for Data Interpretation; John Wiley and Sons, Inc.: Hoboken, NJ, 2007; p. 818.
32. McLuckey, S. A.; Habibi-Goudarzi, S. Decompositions of Multiply Charged Oligonucleotide Anions. J. Am. Chem. Soc. 1993, 115, 1208512095. 